\title{
Okul Müdürlerinin Paternalist Liderlik Davranışları Ölçeğinin Geliştirilmesi; Geçerlik ve Güvenirlik
} Çalışması ${ }^{1}$

\begin{tabular}{lccc}
\hline MAKALE TÜRÜ & Başvuru Tarihi & Kabul Tarihi & Yayın Tarihi \\
Araştırma Makalesi & 19.04 .2019 & 20.03 .2020 & 01.04 .2020 \\
\hline
\end{tabular}

\author{
Ahmet Saylik \\ Siirt Üniversitesi \\ İnayet Aydın \\ Ankara Üniversitesi
}

\section{Öz}

Örgütsel ve yönetsel bir yaklaşım olarak paternalist (babacan) liderliğin Asya toplumlarında çok derin kültürel bir mirasa dayandırılarak genel anlamda olumlu bir değer ve işlevsel bir yaklaşım olarak ele alındığı görülmektedir. Paternalist liderliğin boyutlarını belirlemeye dönük çalışmalar kavramı, genelde hayırseverlik, ahlakilik ve otoriterlik boyutları ile sınırlı tutmuşlarsa da paternal yaklaşımların esasında sömürücü olduğu, özerkliğe bir takım sınırlamalar getirdiği, bir tür müdahalecilik barındırdığı, yararlanıcıyı yetersiz bulduğu, otoriterliği baba şefkati ve sevgisiyle maskelediği belirtilmektedir. Bu araştırmanın amacı, okul müdürlerinin paternalist liderlik davranışlarını ölçebilecek güvenilir ve geçerli bir ölçme aracı geliştirmektir. Bu amaçla Ankara ili Mamak, Gölbaşı ve Çankaya ilçe merkezlerindeki ilkokullarında görev yapan 245 öğretmen üzerinde uygulama yapılmıştır. Araştırmada uzman görüşlerine başvurulmuş böylece kapsam geçerliği sağlanmıştır. Analizler, açıklanan varyansın $\% 67.16$ ve yapının 5 faktörden oluştuğu belirlenmiş, uyum indekslerinin iyi düzeyde olduğunu ortaya koymuştur. Ölçeğin güvenirlik analizi için Cronbach Alfa katsayısı, ölçek maddelerinin ayırt ediciliği için ise düzeltilmiş madde toplam korelasyonları incelenmiştir. Analizler sonucunda ölçeğin güvenilir bir ölçme aracı olduğu saptanmıştır.

Anahtar sözcükler: Paternalist liderlik, okul müdürlerinin liderlik davranışları, ölçek geliştirme, geçerlik, güvenirlik.

${ }^{1} \mathrm{Bu}$ çalışma, Prof. Dr. İnayet Aydın tarafından geliştirilen Paternalist Yönetici Ölçeği esas alınarak daha sonra yine Prof. Dr. İnayet Aydın danıșmanlığında Ahmet Saylık tarafından hazırlanan "Okul Müdürlerinin Paternalist (Babacan) Liderlik Davranışları ile Hofstede'nin Kültür Boyutları Arasındaki İlişki” konulu doktora tezi kapsamında yeni boyutlar eklenerek geliştirilmiştir. Araştırma, Ankara'da 2017 yılında düzenlenen EYFOR-8 Uluslararası Eğitim Yönetimi Forumunda sözlü bildiri olarak sunulmuştur. ${ }^{2}$ Sorumlu Yazar: Dr. Öğr. Üyesi, Eğitim Fakültesi, Eğitim Bilimleri Bölümü, Eğitim Yönetimi Anabilim Dalı, E-posta: ahmetsaylik@gmail.com, https://orcid.org/0000-0001-7754-2199

${ }^{3}$ Prof. Dr., Eğitim Bilimleri Fakültesi, Eğitim Bilimleri Bölümü, Eğitim Yönetimi Anabilim Dalı, E-posta: iaydin@ankara.edu.tr, https://orcid.org/0000-0002-7522-8961 
Paternalizm, Latince pater sözcüğünden gelmekle beraber bir baba gibi davranma ya da başka birine çocukmuş gibi davranma eylemlerini belirtmektedir (Suber, 1999). Başka bir deyişle paternalizm bir kişinin, babanın çocuklarına davranmasına benzer biçimde davranması anlamına gelmektedir (Aycan, 2006). Babanın, çocuğun kendi kararlarını almasına izin vermek yerine, baba en iyisini bilir düşüncesiyle çocuk adına karar alması paternalizmin özünü oluşturur (Andre ve Velasquez, 1991). Oxford İngilizce sözlüğü (1971), paternalizmi bir ulusun, topluluğun, bir grup ya da bireyin tıpkı bir babanın evladına yaklaşımı gibi gereksinimlerini karşılama ve bu yolla yaşamını kontrol altına alma iddiası ya da girişimi biçiminde tanımlamaktadır. Agich (2003) ise her ne kadar köklerinin, bebek ve çocukların ebeveynleri tarafından büyütülmesi ve gelişimlerine dayanması bakımından olumlu bir çağrışıma sahip olsa da paternalizmin aşağılayıcı (pejoratif) çağrışımlar taşıyan son derece sorunlu bir kavram olduğunu da belirtmektedir. Çünkü Agich'e (2003) göre paternalizm, devlet, özel kuruluş ya da bir birey tarafindan, değişen derecelerde baskı ve zorlama yoluyla başka bir bireyin ya da bireyler topluluğunun görüşüne dayatmada bulunmadır. Bu açıdan bakıldığında paternalizm, bir kimsenin, başka bir bireyin iyiliği için onun özgürlüğüne müdahale etmesidir. Böylece birey ya da grupların kendini yönetme yeterliği olan özerklikleri ihlal edilmiş olmaktadır (Häyry, 1998). Baskı ve zorlama barındırsa da altında yatan temel niyetin karşı tarafı koruma onun iyiliğini düşünme olduğu biçiminde yaklaşımlar da söz konusudur. Nitekim Beauchamp ve Childress (1994) paternalizmi, baskın olan bir kişinin bir diğerinin bilinen tercih ya da eylemlerini onun iyiliğine ve onu zararlardan koruma amacıyla geçersiz kılması biçiminde tanımlamaktadırlar. Dolayısıyla paternalizm insanlar adına karar vermek olarak tanımlanabilir (Shinebourne ve Bush, 1994). Aydın'a göre (2017) Paternalizm iki önemli değerin çatışmasını içerir: 1) Bireylerin yaşamlarını nasıl sürdüreceklerine ilişkin kendi kararlarını verme özgürlüğü, 2) Başkalarının iyiliğini sağlama ve koruma sorumluluğu. $O$ halde paternalizmde birinin daha güçlü olduğu iki taraf (birey-birey, devlet-birey) ve taraflardan güçlü olanın güçsüz olanı sözde koruma ve iyilik yapma vaadiyle seçim hakk1 ve özgürlüğüne doğrudan müdahale etmesi söz konusudur.

\section{Paternalizmin Tarihi Kökleri}

Sıradizine (hiyerarşiye) saygı, hayırseverlik ve ahlakilik gibi temel öğelere vurgu yapması bakımından, paternalizmin köklerinin ilk olarak Konfüçyanizme dayandığı belirtilmektedir (Cheng, 1995; Farh ve Cheng, 2000; Redding, 1990; Silin, 1976; Westwood, 1997). Lau'ya (2012) göre Konfüçyus geleneğindeki baba-oğul ilişkisi, yüceltilmiş ve neredeyse bütün sosyal ilişkilerde gözlemlenen bir olguya dönüşmüsstür. Babalık gibi erdemli bir rolün gereği olarak baba, çocukları ve diğer aile bireyleri üzerinde meşru bir yetkiye sahiptir. Zamanla politik bir zemine oturtulan Konfüçyanizm, üstün astına mutlak bir güç ve otorite sergilemesine yasallık kazandırmıștır. Daha sonraları sıradizinsel (hiyerarşik) örgüt yapılanmalarının hemen her formuna yaygınlaştırılan bu kadim gelenekte, çalışanlar liderlerinin kendilerinin üzerinde mutlak bir güç ve otorite kurma hakkına itaat etmek zorunda kalmışlardır. $\mathrm{Bu}$, önemli bir kültürel ayırım olan güç mesafesiyle doğrudan ilişkilidir. 
"Babacanlık" ya da "pederşahilik" olarak da adlandırılan paternalizmde ast ve üst arasındaki ilişki ebeveyn-evlat ilişkisine benzemektedir. Bu yaklaşımda üst astını korur, ona yol gösterir ve onun iyiliği için onun adına kararlar alabilirken ast da bunun karşılığında üstüne büyük bir bağlılık içerinde itaat eder. Paternalizmin kökeni aile ve devlet içerisindeki geleneksel patriarkal (ataerkil) yapıya dayanmaktadır. Bu iki temel kurumdaki yapı zamanla işyerlerine, örgütlere de taşınmıştır (Aycan ve Kanungo, 2000). Bundan hareketle bireylerin toplumsal kültürünü yansitan informal yapı ve değerlerini mensubu oldukları formal örgütlere taşıdıkları belirtilebilir.

Batı'nın kültürel öğelerine özgü geliştirilen bir liderlik modelinin Doğu'nun toplumsal ve kültürel karakterlerini taşıyan bir yapıya uygulamanın çok doğru sonuçlar vermeyebileceği (Farh ve Cheng, 2000) yönündeki tartışmalara koşut olarak Çin, Endonezya, Malezya, Hong Kong, Singapur ve Tayvan gibi Asya ülkelerindeki ekonomik ve gönenç düzeyindeki sistematik artış ve gelişmeler, araştırmaları bu ülkelerin liderlik yaklaşımlarına yönlendirmiştir. 1976'da Silinle başlayıp, 1990'da Redding, 1997'de Westwood ve 2000'de Farh ve Cheng ile devam eden nitel çalışmalar, sonrasında ise yapılan çok sayıda ampirik çalışma (Aycan ve diğ., 2000; Aycan, 2006; Farh ve Cheng, 2000; Cheng, Chou ve Farh, 2000; Farh, Cheng, Chou, ve Chu, 2006; Mathur, Aycan ve Kanungo, 1996; Pellegrini ve Scandura, 2006) bu konuda önemli bulgulara ulaşmıştır. Sonuçta emik (yerel) bir düzlemde, Asya tipi bir yaklaşım olan paternalist liderlik ortaya çıkmıştır.

\section{Paternalist Liderlik}

Liderlik ve yönetim alanyazınında (literatüründe) görece yeni bir girişim olan paternalist liderliğin, Çin, Pasifik Asya, Ortadoğu ve Latin Amerika gibi bölgelerde de sık rastlanılan bir liderlik biçimi olduğu kültürlerarası liderlik çalışmalarında ortaya konulmuştur (Aycan ve diğ., 2000; Farh ve diğ., 2006; Martínez, 2003, 2005; Pellegrini ve Scandura, 2006; Uhl-Bien, Tierney, Graen ve Wakabayashi, 1990).

Alanyazınında paternalist liderlik ile bazı örgütsel değişkenler arasındaki ilişkiyi inceleyen araştırmalar bulunmaktadır. Yapılan araştırmalarda paternalist liderlik örgütsel yurttaşlık (vatandaşlık) (Chu ve Hung, 2009; Ersoy, Born, Derous ve Van Der Molen, 2012; Chu ve Hung, 2009), örgütsel adalet (Pellegrini, 2006), çalışanların psikolojik sağlıkları (Chen ve Kao, 2009), örgütsel bağlılık (Erben ve Güneşer, 2008; Pellegrini, Scandura ve Jayaraman, 2010; Saher, Naz, Tasleem, Naz, ve Kausar, 2013), lider-üye etkileşimi (Ansari, Ahmad ve Aafaqi, 2004; Chu ve Hung, 2009), örgütsel performans (Chen, Eberly, Chiang, Farh ve Cheng, 2014; Cheng ve Jen, 2005), iş stresi (Yeh, Chi ve Chiou, 2008), iş doyumu (Pellegrini ve diğ., 2010; Sun ve Wang, 2009; Yardımc1, 2010; Yetim ve Yetim, 2006), iş güdülemesi (motivasyonu) (Chou, 2012; Niu, Wang ve Cheng, 2009) örgütsel adalet (Köksal, 2011) ve kültür değerleri (Saylık, 2017) gibi değişkenlerle ilişkisine bakılmıştır.

\section{Paternalist Liderliğin Boyutları}

Paternalizme yönelik çözümlemeler bazı tartışmalı konuları gündeme getirmektedir. Paternalist liderliğin kültürel bağlarla organik ilişkisi olduğu varsayımı bağlamın Doğu ve Batı alanyazınında farklı şekillerde ele alınması sonucunu 
doğurmuştur. Esasında Kuzey Amerika ve Avrupa başta olmak üzere özellikle İngilizce konuşulan kültürler, Doğu kültür kümelerinin paternalist liderliği arzu edilen ve işlevselliğine inanılan bir yaklaşım olarak ele alması noktasında ciddi eleştiriler getirmektedir. Bu çalışmada paternalist liderliği emik-etik (yerel-evrensel) bir zemine kaymadan boyutlarını ortaya koyma çabası güdülmüştür. Bu yapılırken de Avrosentik (Batı merkezci) bir dar kalıba girmemeye özen gösterilmiş̧ir. Paternalist liderliğin Doğu kültürü özellikle de Konfüçyan gelenekle tarihsel bağları olması olgu ve kavramın nesnel bir mercekle ele alınmasını gölgelemiş görünmektedir. Paternalist liderliğin boyutlarını belirlemeye dönük çalışmalar (Cheng, Chou, Wu, Huang ve Farh, 2004; Farh ve Cheng, 2000; Farh ve diğ., 2006; Pellegrini ve Scandura, 2006) kavramı, genelde hayırseverlik, ahlakilik ve otoriterlik boyutları ile sinırlı tutmuşlardır. Bu yaklaşımdan kısmen farklılaşan çalışmalar olsa da (Aycan, 2006) paternalizmin özünde özgürlük ve özerkliğe bir takım sınırlamalar getirmesi, paternal eylemlerin bir tür müdahalecilik barındırması, paternalistin yararlanıcıyı yetersiz bulması, belirtilen bu yaklaşımların da otoriterlikle beslenmesi-sürdürülmesi neredeyse hiçbir çalışmada ortaya konmamıştır. Paternalist liderlik, Doğu kültürü ile uyumluluğu dolayısıyla olumlanmış, yukarıda sözü edilen özellikleri görmezden gelinmiştir.

\section{Paternalizm ve Özgürlük-Özerklik}

Özerklik, Yunanca öz, ben, kendim anlamına gelen autos ve yasa, kural anlamındaki nomos'un bir araya gelmesinden oluşan kavramdır (Cevizci, 2000). Özerklik, kapsam olarak bağımlı olmayan bir eylem biçimi; paternalizm de bir bireyin istek ve umutlarının aksine hayırseverlik adına zorlayıcı eylem olarak tanımlanmaktadır (Cohen, 1985). Özerkliğin bağımsız davranma, paternalizmin ise bir şeye zorlama olduğu düşünüldüğünde iki kavram arasında derin bir karşıtllğın söz konusu olduğu görülmektedir.

Sennett, (çev. 2005) paternalist gücün vaatlerinin aldatıcı ve aşağılayıcı olduğunu ileri sürmektedir. Bu aşağılayıcılık, kendini bana teslim et, ben sana bakarım; sana nasıl bakacağımı ben bilirim şeklindeki yaklaşımdan beslenmektedir. Ancak Kant'a (çev. 1995) göre özerklik, akıl sahibi varlığın temel değeridir. Bir eğitim ideali olarak özerkliğin etimolojik kökeni itibariyle öz, kendi kendine, öz anlamındaki auto kavramının varoluşçu kökeni itibariyle en yakın ilişkili olduğu kavram biricikliktir. Biricik olmanın akıl ile ilişkisi göz önünde bulundurulduğunda bireyin kendi amillerinin (etmen, sebep) derin bir yansitıcısı ve değerlendiricisi olduğu düşünülmektedir. Nomos, akıl ve ortaya koyduğu ölçütlerle doğrudan ilişkilidir. Her ne kadar akla sınır çizme düşündürücü görülse bile bireysel özerklik bağlamında önemli görülmektedir (Beaver, 1987). Bu bağlamda birey kendi eylem ve kararlarının yansıtıcısı ve değerlendiricisi değilse, özerkliğini dahası yeganeliğini (biricikliğini) yitirmektedir. Aklın insanın en temel ayırımı (hassa) olduğu düşünüldüğünde ise kendisini insan yapan esas yetisini kaybetmesi kendisini sıradan bir canlı seviyesine düşürmektedir.

Paternalizm ile ilgili etik sorun, bir kimsenin himayesinde olan bireylere, durum ne olursa olsun, paternalist bir yaklaşımla davranma hakkını nasıl kendilerinde 
gördükleri olmuştur. Bu nedenle paternalizm özerklik ve seçme hakkı gibi bireysel hakların ihlali olarak görülmektedir (Blokland, 1997). Gray’e (2013) göre paternalizm, insanları güvenlikleri özgürlüklerinden daha önemliymiş gibi kendi kendilerinden korumaya çalıştığını belirtmektedir. Oysa Mill (2009) yararlılık ilkesi için özerklikten vazgeçmenin kabul edilebilir bir şey olmadığını dolayısıyla bireysel paternalizmden mutlak biçimde kaçınılması gerektiğini belirtmektedir.

\section{Paternalizm ve Müdahalecilik (Interventionism)}

Paternalizm, karşısındakinin yaşamına bir tür müdahale etme yaklaşımı olarak değerlendirilmektedir (Agich, 2003; Aycan, 2006; Conly, 2013; Dworkin, 2002; Harris, 1985; Husak, 2010; Mill, 2009; Miller, 2003; Paulo, 2015; Shinebourne ve Bush, 1994; Van De Veer, 2014; Veatch ve Spicer, 1994). Bu müdahale çoğu zaman karşısındakinin istek ve kararlarına saygı duymaksızın (Harris, 1985) ve istemediği bir biçimde davranılması (Dworkin, 1983) olarak meydana gelmektedir.

İfade özgürlüğünün hiçbir biçimde sınırlandırılmaması gerektiğini belirten Mill, eylem özgürlügünde ise eylemin kişinin kendisini ve başkasını ilgilendirmesini ölçüt almaktadır. Mill'e göre eylemin sadece eylemciyi etkilemesi durumunda da hiçbir şekilde müdahale edilmemelidir. Çünkü kişi, kendisinin tek egemeni olmalıdır. Hatta Mill'e göre eylem başkasına zarar verme anına kadar da özgür olmalıdır. Söz konusu zarar somut bir durum almaya başladığında ise müdahale gerektirir (Mill, 2009). Dolayısıyla bireyi ilgilendiren hiç bir hususta hiç bir müdahalenin meşru görülemeyeceği ancak başkası devreye girdiği zaman müdahalenin meşruiyet kazandığı söylenebilir.

Paternal yaklaşımda ortaya çıkan müdahalenin altında yatan niyetin gerçekten yararlanıcının salt yararını mı yoksa paternalistin örtük ve ahlaki olmayan çıkarlarını mı koruduğu bir diğer tartışma konusudur. Kim (1994) niyet meselesinin, paternalizmin hayırsever ya da sömürücü olup olmadığını belirlediğini ileri sürmektedir. Paternalizmin sömürücü (exploitative) bir yanı olduğu (Uhl-Bien ve Maslyn, 2005; Aycan, 2006) dolayısıyla da temelde vaat ettiği kadar hayırsever olmayabileceği (Pellegrini ve Scandura, 2008) ileri sürülmektedir.

Birisinin iyiliği için onayını aramaksızın davranışta bulunma, üstelik kişiye olan ilgiyi onun özgürlüğünün ihlali pahasına gerçekleşmesinin altında yatan sayıltı, paternalistin iyiliği için eylemde bulunduğu kişiden daha sağlıklı ve akıllıca kararlar verebildiğine ilişkin inancı veya varsayımıdır (Gray, 2013). Apaçık bir güç mesafesiyle beslenen paternal iliş̧ide (güçlü paternalist-güçsüz yararlanıcı, muhtaç) paternalistin karşısındakini yetersiz bulması söz konusudur. Üst-ast, danışmandanışan, öğretmen-öğrenci, doktor-hasta, baba-evlat gibi ikili ilişkilerde görece daha yetkin ve uzman konumunda olan paternalist, karşısındakinin kendisi için en iyi olan seçimi yapamadığı ya da kendisinin tercihine göre daha kötü bir tercihte bulunduğu sayıltısıyla müdahale etmesi söz konusudur.

Paternalist liderin astlarının özel yaşamlarına kadarki müdahalesinin gerçekten çalışanların iyiliği için mi yoksa başka niyetlere hizmet etmesi için mi olduğu (Aycan, 2006) literatürdeki kör noktalardan biridir. Bu olası niyetler, paternalist liderliğin 
ahlaki boyutunu eleştirilerin odağı yapmaktadır. Alanyazınında ahlakilik, paternalizmin bu belirsizliğini temize çıkarma girişimi şeklinde bir temel boyut olarak ileri sürülmüşse de yeterince temellendirilmediği görülmektedir.

\section{Paternalizm ve Yetersiz Bulma (Finding Inadequacy)}

Paternalizmin en temel özelliklerinden birinin paternalistin muhtaç bireyi rasyonel düşünme ve kararlar alma, bilgiyi kullanma, çözümleme, çıkarımlarda bulunabilme gibi bilişsel işlevler bakımından kendine göre yetersiz bulması olduğu söylenebilir. Aycan (2006) paternalistik toplumlarda gücün insanlar arasında eşitsiz biçimde dağıldığını ve bunun etkilerinin itirazsız onay gördüğünü belirtmektedir. Ona göre bu etkilerin başında paternalistin kendini bilgi, yetenek, deneyim ve ahlaki bakımından muhatabından üstün görmesidir.

Paternal davranan birey karşısındaki için senin için en iyinin ne olduğunu ben bilirim düşüncesi içerisindedir ve bunu bir biçimde çevresine hissettirmeyi de bu rolün bir parçası ve gereği olarak hissettirmektedir. Aycan’a (2006) göre paternalistin bu konumu, onun yaşına, deneyimlerine ve konumuna yüklenen anlam sayesinde güç ve otorite kazanmakta ve böylece bütünüyle meşrulaşmaktadır. Cheng (1995) ise paternalistin, çalışanı yetenekleri bakımından küçümsemesi suretiyle heybet ve korku yaymaya çalıştı̆̆ını ileri sürmektedir.

Paternalizmde sistematik bir bilişsel yetersizlik ve taraflar arasında yetersiz ya da bakışımsız (asimetrik) bir bilgi söz konusudur (Cserne, 2008). Bu bağlamda kendisine paternalist yaklaşılan bireyin bilişsel olarak yetersiz olduğu sanısının zararlı psikolojik sonuçları olabilmektedir (Miller, 2003). Yararlanıcının paternalist ilişkideki gönüllülüğü olumsuz psikolojik etkileri kısmen hafifletse de tamamen ortadan kaldırdığı düşünülmemelidir.

Yapılan araştırmalar (Silin, 1976; Westwood, 1997; Westwood ve Chan, 1992) paternalistin özellikle de yönetim alanında astları üzerinde eğitici-öğretici (didaktik) bir rolü olduğunu belirtmektedir. Paternalist liderliğe ait olduğu belirtilen bu temel özellik üst ile ast arasında eşit olmayan bir bilgi birikimi ve temelde astların eğitilmeye muhtaç birer öğrenci olduğu ön kabulünden beslenmektedir. Buna göre paternalist astları için en iyisinin ne olduğunu bilen bir yetkindir.

Yetersiz bulma anlayışı devlet paternalizminde de açık biçimde görülmektedir. Coşkun’a (2000) göre siyaset kuramı açısından, bir yönetim ilişkisi olarak paternalist devlet, yurttaşların bakıma ve yardıma muhtaç, gereksinimlerini karşılama erki olmayan ve hiç büyüyemeyen bir çocuk biçiminde görülmektedir. Yaşamın zorluklarına dair çözümler üretemeyen bu çocuk kendi başına bırakıldığı zaman yaşamını sürdüremeyecektir. Bu nedenle halka kanatlarını açacak ve onları koruyacak güçlü bir otoriteye (devlet) gereksinimleri vardır.

\section{Aile Havası (Family Atmosphere)}

Aycan (2006) paternalist lider işyerinde, çalışanlarına bir baba gibi nasihatlerde bulunarak adeta bir aile havası yaratma, astlarıyla yakın ve bireysel düzeyde ilişkiler geliştirme, çalışanların aile yaşamlarındaki sıkıntılarını bilme ve destek sunma gibi 
yaklaşımlar sergilemektedir. Yöneticinin, çalışanlarının düğün, cenaze, mezuniyet, aile bireylerine yardım ve destek sağlama, ailevi sorunlarında arabuluculuk yapma gibi çalışma dışındaki yaşamlarıyla ilgilenme türünde davranışlar sergilediğini belirtmektedir.

Örgüt ve yönetim bilimindeki üretim odaklı, bilimsel ve yakın denetimli biçimsel yaklaşımlar bekleneni veremeyince örgüte bir aile havası katma yoluyla verimi artırma yoluna gidilmiştir. Bu süreçte "patron babadır" metaforu devreye sokulmuştur. Sennett'e (çev. 2005) göre bu, esasında patronların iş̧̧ilerini sevmediği gerçeğini örtmek üzere yeni ekonominin yaygın olarak başvurduğu bir metafordu. $\mathrm{Bu}$ yolla çalışanı tehdit eden değil, onları psikolojik yönden memnun eden patron imgesi yaratılmıştır. Bu metaforun gücü, başkalarının bakımını üstlenme ve iktidar olgularını bir araya getirmesidir. Tuhaf olmakla beraber sevgi ve iktidarı bir araya getirdiği belirtilebilir. Bu tuhaflık, Batı yazınında sıkça belirtilmektedir.

\section{Otoriterlik (Authoritarianism)}

Otoriter liderlik li-wei (heybet veya korku yayma-inspiring awe or fear) kavramına benzerdir. Otoriter liderlikle kastedilen, çalışanların üzerinde mutlak bir otorite ve kontrol sağlamak, çalışanlardan da sorgusuz biçimde itaat bekleme eğilimi veya davranışıdır (Cheng ve diğ., 2004; Farh ve Cheng, 2000; Farh ve diğ., 2006).

Heybet ve korku yayma, bir liderin kişisel otoritesinin çalışanlara nüfuz etmesini vurgulamaktadır. Liderin heybet ve korku yayma tutumu, kontrol ve baskıyı, çalışanı yetenekleri bakımından küçük görmeyi, yönetici için yüce bir imaj oluşturmayı ve çalışanları bu yolla eğitmeyi içermektedir. Cheng (1995) içerikteki her bir davranış için uygulamadan örnekler vermektedir. Örneğin, liderin kontrol ve baskısı yetkilendirmede isteksizlik, üstten asta olan iletişim, bilgi gizleme ve sıkı bir takip gibi yaklaşımlarla görünür olmaktadır. Buna bağlı olarak çalışanların uyum ve itaat gösterme, lidere kitlesel destek, bariz çatışmalardan kaçınma, liderin buyruklarını koşulsuz kabul etme ve lidere sadakat ve güven sergileme gibi davranışlarda kendini göstermektedir (Farh ve Cheng, 2000).

Weber (1968) paternalizmin otoritenin meşruiyet kazanmış bir biçimi ve geleneksel otoritenin en temel türlerinden biri olduğunu savunmaktadır. Ancak Asya'da ortaya çıkan paternalizm çalışmaları Weber'in salt otoriteryanlık görüşünün aksi niteliklere sahip (Pellegrini ve Scandura, 2008) olduğu iddia edilmektedir. Batı yazınında bir yönetim yaklaşımı olarak paternalizme ilişkin temel tartışmalar yaklaşımın sömürücü olduğu, çalışanların özerkliğinin ihlalini meşrulaştırıp bunu görmezden geldiği, otoriterliği, baba şefkati ve sevgisi katarak maskelediği vb. gibi hususlarda yoğun biçimde ele alınmaktadır. Ancak örgütsel ve yönetsel paternalizmin Asya toplumlarında pek de bu şekilde ele alınmadığı hatta çok derin kültürel köklere dayandırılarak genel anlamda olumlu bir değer ve işlevsel bir yönetsel yaklaşım olarak ele alındığı görülmektedir.

Paternalist liderlik, açık ve güçlü bir otoriteyi, ilgi, nezaket ve ahlaki değerlerle birleştiren bir liderlik tarzıdır (Silin, 1976). Bu yönüyle paternalist liderliğin 
Türkiye'deki örgütlerde etkili bir liderlik tarzı olduğu düşünülmektedir. Ancak okullar diğer örgütlere göre daha özgün yapılara sahiptir.

Türkiye'deki toplumsal kültür içinde paternalist değerlerin önemli derecede yüksek olduğu belirtilmektedir (Aycan ve diğ., 2000). Türkiye'de aile yapısındaki baba ve evlat arasındaki şefkat ve güç mesafesinin, kolektivist (toplulukçu) ve hiyerarşik (sıradizinsel) kültür yapısıyla birleşmesiyle ortaya çıkan ilişki biçiminin zaman içerisinde iş yaşamına da yansıması örgüt yöneticisinin kimliğini de biçimlendirmektedir (Canbolat, Beraha, Çeliksoy ve Türker, 2010). Örgütsel ve yönetsel bir yaklaşım olarak paternalist (babacan) liderliğin Asya toplumlarında çok derin kültürel bir mirasa dayandırılmak suretiyle genel anlamda olumlu bir değer ve işlevsel bir yaklaşım olarak ele alındığı görülmektedir. Paternalist liderliğin boyutlarını belirlemeye dönük çalışmalar kavramı, genelde hayırseverlik, ahlakilik ve otoriterlik boyutları ile sınırlı tutmuşlarsa da paternal yaklaşımların esasında sömürücü olduğu, özerkliğe bir takım sınırlamalar getirdiği, bir tür müdahalecilik barındırdığı, yararlanıcıyı yetersiz bulduğu, otoriterliği baba şefkati ve sevgisiyle maskelediği belirtilmektedir. $\mathrm{Bu}$ araştırma bu yönüyle özgün bir yaklaşım sergilemektedir. dolayısıyla girdisi ve çıktısının insan olduğu en önemli kurumlar olan eğitim kurumlarını yöneten bireylerin paternalist liderlik davranışlarını belirlemek amacıyla geliştirilen Paternalist Liderlik Davranışları Ölçeği'nin alana katkı sunması beklenmektedir.

\section{Yöntem}

$\mathrm{Bu}$ başlık altında araştırma modeli ve çalışma grubu hakkında bilgiler verilmiştir. Ayrıca, araştırma verilerinin toplanması ile veri analizi süreciyle ilgili bilgilere de yer verilmiştir.

\section{Araştırma Modeli}

Ölçek geliştirmenin aşamalı bir biçimde işlem basamakları başlığıyla verildiği bu kısımda sırasıyla; madde havuzunun oluşturulması ve ölçeğin ön uygulama öncesi işlemleri, ön uygulama, madde toplam korelasyonu, açımlayıcı ve doğrulayıcı faktör analizlerine ilişkin bulgular yer almaktadır. $\mathrm{Bu}$ araştırmada betimsel tarama modeli kullanılmıştır.

\section{Çalıșma Grubu}

Ölçek geliştirme sürecinde geçerlik ve güvenirlik analizlerinin yapılabilmesi için uygun örneklem büyüklüğünün ne olması gerektiğine ilişkin alanyazınında bir görüş birliği olduğunu söylemek güçtür. Ancak ölçek geliştirme sürecinde Açımlayıcı Faktör Analizinin (AFA) yapılabilmesi için Kline (1979) ölçekteki madde sayısının en az iki katı, Bryman ve Cramer (2002) ise madde sayısının en az beş katı örneklem büyüklüğüne ulaşılması gerektiğini belirtmektedir. Kline (2005) ise daha açık bir biçimde örneklem sayısının 200'den az olmaması gerektiğini ileri sürmekteyken Hair, Anderson, Babin ve Black, (1998) katılımcı sayısının 100'ün üzerinde olmasının yeterli olabileceğini belirtmektedir. Bu çalışmada madde saysının beş katı olan 265 katılımcıya ulaşılmak hedeflenmiş ancak 251 anket geri dönebilmiştir. Bunların altısı 
inceleme dışında tutulmuş, 245 anket formu üzerinden analizler gerçekleştirilmiştir. Araştırmanın çalı̧̧ma grubunu kamu ilkokullarında çalışan öğretmenler oluşturmaktadır. Katılımcılar, gönüllü olanlardan rastgele seçilmişlerdir.

\section{Verilerin Toplanması}

Okul müdürlerinin paternalist liderlik davranışlarını ölçebilecek bir ölçme aracı geliştirilmesi amaçlanan bu çalışmada öncelikle paternalizme ilişkin yurt içindeki ve yurt dışındaki alanyazın taranmış ve kavrama ilişkin geliştirilen ölçme araçları incelenmiştir. Bunun yanı sıra ön uygulama öncesinde 8 öğretmenle odak grup görüşmesi yapılmış, alanyazından yararlanılarak ilk aşamada 72 maddelik bir havuz oluşturulmuştur.

Ölçeğin görünüş ve kapsam geçerliğinin belirlenebilmesi için, istatistik, ölçme ve değerlendirme, eğitim yönetimi alanlarında uzman kişilerin görüşlerine başvurulmuştur. Ölçmede görünüş geçerliği, ölçme aracının amaca ne derecede hizmet ettiğini alan uzmanlarının öznel yargılarına göre saptayan, ölçme aracının amaca hizmet etme düzeyini ortaya koyan bir geçerlik türüdür. Ölçme aracının içeriğinin beklenilen davranışları ne düzeyde ölçtüğ̆ünü gösteren bir geçerlik türü de kapsam geçerliğidir (Balcı, 2013). Süreç içerisinde belli aralıklarla yapılan değerlendirmeler ve ölçek maddelerinin yapıyı ne derece ölçtüğüne yönelik uzman görüşleri sonrasında madde sayısı 53'e indirilmiş ve böylece deneme formu oluşturulmuştur. 53 maddeyle uygulama yapılmıştır.

\section{Verilerin Analizi}

Geliştirilmeye çalışılan ölçeklerin geçerlik ve güvenirlik analizlerinin yapılabilmesi için uygun örneklem büyüklügünün ne olması gerektiğine ilişkin alanyazında bir görüş birliğinin olduğunu söylemek güçtür. Ulaşılması gereken örneklem büyüklügünün ölçekteki madde sayısının iki katından az (Kline, 1979) ya da beş katından az (Bryman ve Cramer, 2002) olmaması gerektiği belirtilmektedir. Madde sayısından bağımsız olarak örneklem sayısının 200'den az olmaması gerektiği (Kline, 2005) ya da katılımcı sayısının 100'ün üzerinde olmasının yeterli olabileceği (Hair ve diğ., 1998) de ileri sürülen yaklaşımlardır. Bu çalışmada madde saysının beş katı olan 265 katılımcıya ulaşılmak hedeflenmiş ancak 251 ölçek geri dönmüştür. Bunların arasında altı ölçek formu inceleme dışında tutulmuş, 245 ölçek formu üzerinden analizler gerçekleştirilmiştir. Elde edilen veriler SPSS 16.0 (Sosyal Bilimler İçin İstatistik Paket Programı) ve AMOS 16.0 programıyla analiz edilmiştir. Ön uygulama sonucunda ulaşılan verilere geçerlik ve güvenirlik analizleri yapılmış, analizlere ilişkin bulgulara izleyen başlıkta yer verilmiştir.

\section{Bulgular}

$\mathrm{Bu}$ kısımda geçerlik ve güvenirlik analizlerine ilişkin bulgulara yer verilmiştir. Bu amaçla ön uygulamada 53 madde olan ölçek, analizler sonucunda 30 maddelik son şeklini almıştır. 


\section{Geçerlik ve Güvenirlik Analizleri}

Ön uygulama öncesinde ölçekte 53 madde yer almıştır. Ölçeğin güvenirliği, Cronbach'ın Alfa iç tutarlık katsayısının ve madde toplam korelasyonlarının hesaplanması ile test edilmiştir. Madde toplam korelasyonları .45 'in altında olan maddeler değerlendirme dışında bırakılarak geçerlik ve güvenirlik analizleri yinelenmiştir.

Ölçme aracının geliştirme sürecinde yaygın olarak başvurulan AFA ve Doğrulayıcı Faktör Analizi (DFA) yapı geçerliğine ilişkin analizlerdir. AFA, belli bir hipotezin sınamasının olanaklı olmadığı durumlarda, ölçme aracının doğası hakkında bilgi edinilmeye çalışılan (Balcı, 2013), aynı yapıyı veya niteliği ölçen değişkenleri az sayıda faktör ile açıklamaya çalş̧an istatistiksel bir yöntemdir. Verilerin çözümlenmesinde Kaiser-Mayer-Olkin (KMO) güvenirlik katsayısının asgari .70 olması faktör analizinin yapılabilmesi için gerekli bir ölçüttür. Maddelerin faktörlerle olan ilişkisini faktör yük değerleri belirlemektedir. Kaynaklar faktör yük değeri için en az sınırın .30 olması gerektiğini belirtmektedir. Ayrıca faktörlerin açıkladığı varyans oranı faktör yük değerlerinin karelerinin toplamı alınarak hesaplanmaktadır. Ölçeklerde faktörlerin birlikte açıkladığı varyansın en az \% 30 olması gerekmektedir (Büyüköztürk, 2010).

Öte yandan DFA ise, belli bir kuramsal çerçeveye dayanarak geliştirilen hipotezlerin (Balcı, 2013) ve modelin doğrulanıp duğrulanmadığını test etmede (Kline, 2005) kullanılan bir yöntemdir. Bu analiz ileri düzey araştırmalarda gizil değişkenlere dayanan kuramların test edilmesinde kullanılmaktadır. DFA'da en sık rapor edilen uyum indeksleri, $\mathrm{X}^{2}$ / sd (ki karenin serbestlik derecesine oranı) değeri ve ardından CFI (Comparative Fit Index), GFI (Goodness of Fit Index), AGFI (Adjusted Goodness of Fit Index), RMSEA (Root Mean Square Error of Approximation), Root Mean Square Residual (RMR) ve Standardizet Root Mean Square Residual (SRMR) değerleridir (Sümer, 2000).

Ölçme aracının güvenirliğini test etmek ve böylece maddelerin ayırt ediciliğini hesaplamak üzere Cronbach'ın Alfa katsayısı ve madde toplam korelasyonları incelenmiştir. Madde toplam korelasyonu .30 ve üzeri olan maddelerin ayırt ediciliğinin iyi olduğu , faktör analizinde ise faktör yük değerlerinin .45 ve üzerinde olan maddelerin seçiminde iyi bir ölçüt olduğu belirtilmektedir (Büyüköztürk, 2010).

Açımlayıcı faktör analizine ilişkin bulgular. Veri setinin faktör analizi için uygun olduğu KMO değerinin .93 ve Barlett Küresellik Testi sonucunun anlamlı $\left(\chi^{2}\right.$ $=5,519.54, \mathrm{df}=496 p<.01)$ bulunmasıyla kararlaştırılmıştır. Taslak ölçeğin kaç faktörden oluştuğunu belirlemek için açıkladıkları varyans miktarları incelenmiş ve 53 maddenin 5 faktöre dağıldığı belirlenmiştir. Varimax dik döndürme yöntemi ile maddelerin faktörlere dağılımları belirlenmiştir. Araştırmada varimax döndürme türüne başvurulmasının nedeni faktörler arasındaki korelasyonun düşük olmasıdır. Çünkü paternalist liderlik alanyazında hayırseverlik ve otoriterlik gibi iki zıt özelliği barındıran bir kültürel liderlik yaklaşımı olarak bilinmektedir. Faktörler arasında temel alınan korelasyon değeri .30'dur. Analiz sonucunda faktörler sırasıyla 4, 9, 4, 5 
ve 8 maddeden oluşmuştur. Faktörlerin isimlendirilmeleri, maddelerin vurguladığ 1 anlam ve kavramlar esas alınarak yapılmıştır. Buna göre, ilkokullarda görev yapmakta olan okul müdürlerinin çalışanları arasında bir aile havası oluşturmak istemelerine yönelik maddeler birinci faktörde, öğretmenlerine karşı davranışlarının temelinde iyi niyet olmasından dolayı hayırsever olmasına yönelik maddeler ikinci boyutta, sıradizin ve otoriteye ilişkin maddeler üçüncü boyutta, çalışanlarına iş ve iş dışı yaşamda müdahale edebilme yetkisini kendinde görmesine ve dolayısıyla müdahale içeren davranışlarına ilişkin maddeler dördüncü boyutta, çalışanlarını yetersiz görmelerine ilişkin maddeler ise beşinci boyutta toplanmıştır. Buna göre faktörler sırasıyla "Aile Havası", "Hayırseverlik", "Otoriterlik", "Müdahalecilik" ve "Yetersiz Görme" olarak isimlendirilmiştir. Paternalist yönetici davranışları ölçeğine ilişkin faktör ve madde analizi sonuçları Tablo 1'de verilmiştir.

Tablo 1

Paternalist Liderlik Ölçeği Güvenirlik ve Açımlayıcı Faktör Analizleri

\begin{tabular}{|c|c|c|c|}
\hline فำ & Maddeler & $\begin{array}{l}\text { Faktör } \\
\text { Yükleri }\end{array}$ & $\begin{array}{l}\text { Madde } \\
\text { Toplam } \\
\text { Korelasyonu }\end{array}$ \\
\hline & Okul Müdürü: & & \\
\hline \multirow{5}{*}{ 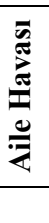 } & 1.Okulda kendisini bir aile büyügü gibi görür. & .84 & .67 \\
\hline & 2.Okulda bir aile ortamı yaratmaya önem verir. & .69 & .69 \\
\hline & 3.Öğretmenlere evladı gibi davranır. & .76 & .73 \\
\hline & $\begin{array}{l}\text { 4.Öğretmenlerin birbirleriyle kardeş gibi geçinmelerini } \\
\text { bekler. }\end{array}$ & .49 & .49 \\
\hline & Açıklanan Varyans: \% 9.1, Özdeğer: 1.19, $\alpha: .82$ & & \\
\hline \multirow{9}{*}{ 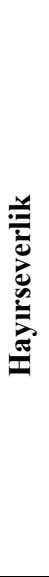 } & $\begin{array}{l}\text { 5. Öğretmenlerini dışarıdan gelebilecek tehditlere karş1 } \\
\text { aile bireyleriymiş gibi korur. }\end{array}$ & .59 & .72 \\
\hline & 6.Öğretmenlere özel yaşamlarıyla ilgili öğütler verir. & .61 & .53 \\
\hline & $\begin{array}{l}\text { 7.İhtiyaçları olduğunda, öğretmenlerine iş dışı konularda } \\
\text { yardım etmeye hazırdır. }\end{array}$ & .73 & .77 \\
\hline & $\begin{array}{l}\text { 8.Öğretmenlerinin özel günlerinde (örn. nikah, cenaze, } \\
\text { mezuniyet vs.) yanlarında olur. }\end{array}$ & .61 & .63 \\
\hline & 9.Öğretmenleriyle tek tek ilgilenmeyi önemser. & .81 & .81 \\
\hline & 10.Öğretmenlerinin kişisel sorunlarıyla ilgilenir. & .84 & .82 \\
\hline & 11.Öğretmenlere karşı iyi niyetlidir. & .52 & .60 \\
\hline & $\begin{array}{l}\text { 12.Öğretmenlerinin aile hayatında yaşadığ } \breve{g} \text { problemlerde } \\
\text { (eşler arası problemler gibi) arabuluculuk yapmaya } \\
\text { hazırdır. }\end{array}$ & .70 & .52 \\
\hline & $\begin{array}{l}\text { 13.Öğretmenlere herhangi bir durumla başa } \\
\text { çıamadıklarında gerekli yardımı, yönlendirmeyi yapar. }\end{array}$ & .70 & .64 \\
\hline
\end{tabular}


Tablo 1 (devam)

\begin{tabular}{|c|c|c|c|}
\hline$\overbrace{0}^{\infty}$ & Maddeler & $\begin{array}{l}\text { Faktör } \\
\text { Yükleri }\end{array}$ & $\begin{array}{l}\text { Madde } \\
\text { Toplam } \\
\text { Korelasyonu }\end{array}$ \\
\hline \multirow{4}{*}{ 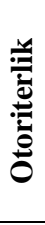 } & $\begin{array}{l}\text { 14.Öğretmenlerin kendi başlarına karar almalarından } \\
\text { rahatsızlık duyar. }\end{array}$ & .69 & .71 \\
\hline & $\begin{array}{l}\text { 15.Verilen görevlerin eleştirilmeden yerine getirilmesini } \\
\text { ister. }\end{array}$ & .77 & .75 \\
\hline & 16.Aldığı kararlara harfiyen uyulmasını bekler. & .80 & .70 \\
\hline & 17.Kurallara uygun olarak yapılmayan ișlere karșı katıdır. & .77 & .62 \\
\hline \multirow{6}{*}{ 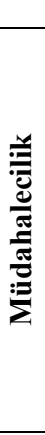 } & Açıklanan Varyans: \% 10.32, Özdeğer: 1.49, $\alpha: .85$ & & \\
\hline & $\begin{array}{l}\text { 18.Öğretmenlerin görünüşlerine (saç-baş, giyim-kuşam) } \\
\text { müdahale eder. }\end{array}$ & .79 & .60 \\
\hline & $\begin{array}{l}\text { 19.Gerektiğinde, öğretmenleri ilgilendiren konularda } \\
\text { onlara danışmadan karar alır. }\end{array}$ & .63 & .71 \\
\hline & $\begin{array}{l}\text { 20.Öğretmenlerin kendi aralarında çözebilecekleri } \\
\text { sorunlara müdahale eder. }\end{array}$ & .79 & .82 \\
\hline & $\begin{array}{l}\text { 21.Özel yaşamını ya da alışkanlıklarını beğenmediği } \\
\text { öğretmenleri eleştirir. }\end{array}$ & .81 & .80 \\
\hline & $\begin{array}{l}\text { 22.Yönetsel karar ve uygulamalarında (görevlendirmeler, } \\
\text { nöbet, ders saatleri, sinıf dağıtımları, araç-gereç } \\
\text { dağıtımları vs.) öğretmenlerin isteklerini gözardı eder. }\end{array}$ & .61 & .70 \\
\hline \multirow{11}{*}{ 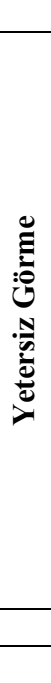 } & Açıklanan Varyans: \% 12.01, Özdeğer: 1.78, $\alpha: .89$ & & \\
\hline & $\begin{array}{l}\text { 23.Öğretmenlere bu okulun müdürü olmasının büyük bir } \\
\text { lütuf olduğunu hissettirir. }\end{array}$ & .69 & .59 \\
\hline & $\begin{array}{l}\text { 24.İşle ilgili konularda öğretmenlerin fikrini sorsa bile } \\
\text { kararı verirken bunları dikkate almaz. }\end{array}$ & .64 & .75 \\
\hline & 25.Yetkilerini öğretmenlerle paylaşmaktan kaçınır. & .67 & .69 \\
\hline & $\begin{array}{l}\text { 26.Okulda olmadığında oluşabilecek sorunları } \\
\text { öğretmenlerin çözemeyeceğini düşünür. }\end{array}$ & .75 & .73 \\
\hline & $\begin{array}{l}\text { 27.Okulu yönetmenin sadece yöneticinin işi olduğuna } \\
\text { inanır. }\end{array}$ & .79 & .81 \\
\hline & $\begin{array}{l}\text { 28.Öğretmenlerin, kendisinin içinde olmadığı herhangi bir } \\
\text { işte başarılı olamayacaklarını düşünür. }\end{array}$ & .74 & .79 \\
\hline & $\begin{array}{l}\text { 29. Öğretmenler adına karar verme hakkını kendinde } \\
\text { görür. }\end{array}$ & .73 & .76 \\
\hline & $\begin{array}{l}\text { 30.Öğretmenlerin başarılarında kendisinin büyük katkısı } \\
\text { olduğunu düşünür. }\end{array}$ & .78 & .71 \\
\hline & Açıklanan Varyans: \% 18.56, Özdeğer: 11.35, $\alpha: .92$ & & \\
\hline & Toplam Varyans: \% 67.16, KMO:.93, $\alpha: .80$ & & \\
\hline
\end{tabular}

Tabloda maddelerin faktör yük değerlerinin .49 ile .84 aralığında değiştiği görülmektedir. Maddelerin toplam korelasyonları birinci faktörde .49 ile .73 ve Cronbach Alfa güvenirlik katsayısı $\alpha=.82$; ikinci faktörde .52 ile .82 ve $\alpha=.90$; üçüncü faktörde .62 ile. 75 ve $\alpha=.85$; dördüncü faktörde .60 ile .82 ve $\alpha=.89$; beşinci 
faktörde ise .59 ile .79 ve $\alpha=.92$; olduğu tespit edilmiştir. Vasat değer sayılabilecek iki madde (4 ve 11) dışında diğer bütün maddeler iyi ile mükemmel değer aralığında bir yüke sahiptir. Bu da maddelerin ilgili faktörle güçlü bir şekilde ilişkili olduğunu göstermektedir.

Doğrulayıcı faktör analizine ilişkin bulgular. Geliştirilen Paternalist Yönetici Davranışları Ölçeği’nin açımlayıcı yöntemin iddia ettiği modeli sınamak ve modelin uygunluğunu test etmek için ikinci düzey doğrulayıcı faktör analizi yapılmıştır. İkinci düzey doğrulayıcı faktör analizi sonuçlarına göre, hangi göstergelerin tanımlanan model içerisinde yer alması gerektiğine karar verildikten sonra, uyum ölçütleri göz önüne alınarak modelin uygunluğu tartışılmıştır. Modelin uygunluğu açısından öncelikle $p$ değeri kontrol edilmiştir. Daha sonra ise RMSEA, CFI, GFI, AGFI, NFI ve RMR gibi alternatif uyum endeksleri değerlendirmeye alınmıştır. Öte yandan araştırmada başvurulan kestirim yöntemi, değişkenlerin dağılımlarının çok değişkenli normal ve sürekli olmalarından dolayı en çok olabilirlik (Maximum likelihood, ML) olarak belirlenmiştir. Araştırma, ML için örneklemin geniş olması (en az 300) koşulunu sağlamada kısmen yetersiz kalmaktadır. Yapılan analizler sonucunda, modelin uygunluğuna ilişkin hesaplanan uyum değerleri Tablo 2'de verilmiştir.

Tablo 2

Doğrulayıcı Faktör Analizi Modelinde Uyum İndeksi Değerleri

\begin{tabular}{lccc}
\hline Uyum Ölçütü & Mükemmel Uyum & Kabul Edilebilir Uyum & Paternalist L. Ölçeği \\
\hline $\mathrm{p}$ değeri & $.05<\mathrm{p} \leq 1.00$ & $.01 \leq \mathrm{p} \leq .05$ & .00 \\
$\chi^{2} / \mathrm{df}$ & $0 \leq \chi^{2} / \mathrm{df} \leq 2$ & $2<\chi^{2} / \mathrm{df} \leq 3$ & 1.40 \\
RMSEA & $0 \leq \mathrm{RMSEA} \leq .05$ & $.05<\mathrm{RMSEA} \leq .08$ & .04 \\
NFI & $.95 \leq \mathrm{NFI} \leq 1.00$ & $.90 \leq \mathrm{NFI}<.95$ & .90 \\
$\mathrm{CFI}$ & $.96 \leq \mathrm{CFI} \leq 1.00$ & $.90 \leq \mathrm{CFI}<.95$ & .97 \\
GFI & $.91 \leq \mathrm{GFI} \leq 1.00$ & $.85 \leq \mathrm{GFI}<.90$ & .88 \\
AGFI & $.90 \leq \mathrm{AGFI} \leq 1.00$ & $.85 \leq \mathrm{AGFI}<.90$ & .85 \\
\hline
\end{tabular}

Analizler sonucunda, modelin uygunluğuna ilişkin hesaplanan uyum değerleri RMSEA için .04, CFI için .97, GFI için .88, NFI için .90 ve AGFI için ise .85 olarak bulunmuştur. AGFI değeri kabul edilebilir alt sınırında yer almakta dolayısıyla görece düşük bir değere sahiptir. Bunun nedeni örneklem hacminin görece düşük olması olabilir. Çünkü AGFI de GFI gibi örneklem büyüklüğünden etkilenen uyum indeksleridir. Şekil 1'deki diyagram modele ilişkin yapıyı göstermektedir. 


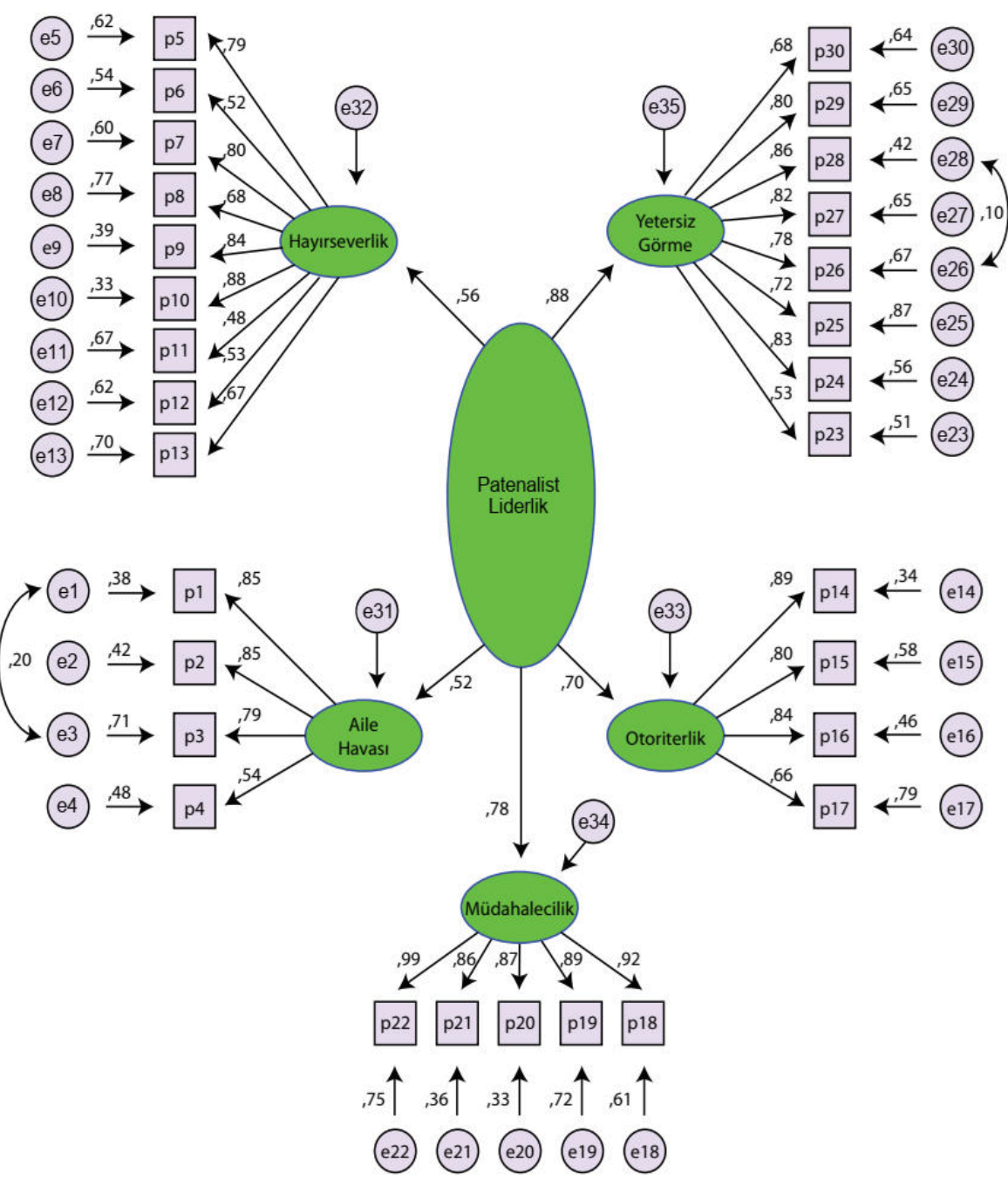

Chi-Square $=515,830, \mathrm{df}=367, \mathrm{P}$-value $=000, \mathrm{RMSEA}=, 041$

Şekil 1. İkinci düzey DFA (standart katsayılar)

Şekil 1'de aile havası alt faktörüne ait maddelere ilişkin korelasyon katsayıları .49 ile .73 arasında; hayırseverlik .52 ile .82 arasında; otoriterlik .62 ile .75 arasında; müdahalecilik .60 ile .82 arasında; yetersiz görme ise .59 ile .81 arasında değişmektedir. Modelin uygunluğu ve maddeler arasında korelasyonun iyi düzeyde olduğu görülmektedir $\left(\chi^{2}=515,83 ; \mathrm{sd}=367 ; \mathrm{p}<.01\right)$. Araştırmada maddeler 
arasındaki korelasyonların ve 30 maddeyi beş boyutta tanımlayan modelin, kabul edilebilir olduğunu göstermektedir.

\section{Tartışma, Sonuç ve Öneriler}

Kültürler arasında yönetsel tutumlar, değerler ve davranışlar farklılık göstermektedir. $\mathrm{Bu}$ yaklaşım okul müdürleri nasıl bir liderlik anlayışı ile okulu yönetmelidir sorusunu önemli kılmaktadır. Bu anlamda Batı'da üretilen liderlik ve yönetim yaklaşımları gerçekten, belirgin farklılıklara karşın, bütün kültürlerde işlevsel olabilir mi? Avrupa ve Amerika'da ortaya çıkan liderlik tarzları Doğu toplumlarıyla uyumlu değilse, deyim yerindeyse doku uyuşmazlığı söz konusuysa bu durumda yapılması gereken en doğru şey, kültür değerleriyle uyumlu yönetim yaklaşımları ortaya koymak değil midir? Bu ve benzeri sorular paternalist liderlik ölçeğinin geliştirilmesinin önemini ortaya koymaktadır.

Paternalist Yönetici Davranışları Ölçeği, okul müdürlerinin paternalist davranışlarını ölçmek amacıyla geliştirilmiş toplamda 30 madde ve beş alt boyuttan oluşan bir ölçme aracıdır. Aile Havası boyutu, okul içinde ve dışında çalışanlar arasında bir aile havası oluşturma düzeylerini ölçmektedir. Dört maddeden oluşan bu alt boyuttan elde edilebilecek yüksek puan, okul müdürlerinin okul içinde ve dişında çalışanlar arasında bir aile havası oluşturmaya yönelik davranış düzeyinin yüksek olduğuna işaret etmektedir. Hayırseverlik boyutu, okul müdürlerinin yönetsel tutum ve davranışlarındaki iyi niyet düzeyini ölçmektedir. Bu alt boyutta dokuz madde bulunmakta ve elde edilebilecek yüksek puan, okul müdürlerinin paternalist davranışlarında hayırseverlik düzeyinin yüksek olduğunu belirtmektedir. Otoriterlik boyutu, okul müdürlerinin otoriter davranma düzeylerini ölçmektedir. Dört maddeden oluşan bu boyuttan elde edilebilecek yüksek puan, okul müdürlerinin otoriter davranma düzeylerinin yüksek olduğuna işaret etmektedir. Müdahalecilik boyutu, okul müdürlerinin öğretmenlerine müdahalede bulunma düzeylerini ölçmektedir. $\mathrm{Bu}$ alt boyutta beş madde yer almaktadır. Elde edilebilecek yüksek puan, okul müdürlerinin müdahaleci davranma düzeylerinin yüksek olduğuna işaret etmektedir. Yetersiz Görme boyutu ise, okul müdürlerinin öğretmenlerini yetersiz bulma düzeylerini ölçmektedir. Bu alt boyutta sekiz madde yer almakta ve yüksek puan, okul müdürlerinin çalışanlarını yetersiz görme düzeylerinin yüksek olduğuna işaret etmektedir.

Ölçek toplam puan üretmektedir. Ölçekten alınabilecek en düşük puan 30, en yüksek puan 150'dir. Yüksek puan, okul müdürlerinin yüksek düzeyde paternalist davrandığını göstermektedir. Ölçekte olumsuz ifadeler ve dolayısıyla ters yönde puanlanma yoktur. Ölçeğin alt boyutlarına ilişkin Alfa katsayılarının yüksek olması (Aile havası $=.82$, Hayırseverlik $=.90$, Otoriterlik $=.85$, Müdahalecilik $=.89$ ve Yetersiz Görme $=.92$ ), alt boyutlarda yer alan maddelerin birbiriyle tutarlı olduğunu göstermektedir. AFA ve DFA sonuçları da ölçeğin geçerliğini kanıtlamaktadır.

Yapılan açımlayıcı ve doğrulayıcı faktör analizleri sonucunda ulaşılan bulgular 1şığında, Paternalist Liderlik Ölçeği, okullarda görev yapan müdürlerin öğretmenlerle 
ilişkilerinde, yönetsel karar ve uygulamalarında ortaya koyduğu paternalistik (babacan) davranışları ölçebilecek yeterli psikometrik özelliklere sahip bir ölçme aracı olduğu söylenebilir.

Araştırmada ulaşılan bilgi ve bulgular ışığında araştırmacılar için; paternalist liderliğe ilişkin Türkiye geneli, dolayısıyla bölgesel farklılıkları ortaya koyabilecek geniş katılımlı çalışmalar önerilebilir. Çünkü paternalist liderlik ile güç mesafesi, kolektivizm, erillik gibi kültür değerleri arasında yakın bir ilişki söz konusudur. Farklı eğitim kademeleri ve okul türlerinde okul müdürlerinin paternalist liderlik yaklaşımlarını ve varsa farklılıklarını ortaya koyan araştırmalar yapılabilir. Toplumsal kültür değerlerinin, paternalist liderlik üzerinde etkisinin olduğundan hareketle, karar vericiler için ise, okul yöneticilerine sosyoloji, toplumsal psikoloji gibi disiplinlerde lisansüstü eğitim yapmalarının, liderlik, kültür ve değerler temalı hizmet içi eğitim seminer ve kurs olanaklarının sağlanması önerilmektedir.

\section{Kaynakça}

Agich, G. (2003). Dependence and autonomy in old age: An ethical framework for long-term care. Cambridge: Cambridge University Press.

Andre, C., and Velasquez, M. (1991). For your own good. Issues in Ethics, 4(2). Retrieved

from https://legacy.scu.edu/ethics/publications/iie/v4n2/owngood.html

Ansari, M. A., Ahmad, Z. A., and Aafaqi, R. (2004). Organizational leadership in the Malaysian context. In D. Tjosvold and K. Leung (Eds.), Leading in high growth Asia: Managing relationship for teamwork and change (pp. 109-138). Singapore: World Scientific.

Aycan, Z. (2006). Paternalism: Towards conceptual refinement and operationalization. In K. S. Yang, K. K. Hwang, and U. Kim (Eds.), Scientific advances in indigenous psychologies: Empirical, philosophical, and cultural contributions (pp. 445-466). London: Cambridge University Press.

Aycan, Z., Kanungo, R., Mendonca, M., Yu, K., Deller, J., Stahl, G., and Kurshid, A. (2000). Impact of culture on human resource management practices: A 10country comparison. Applied Psychology, 49(1), 192-221. doi: 10.1111/14640597.00010

Aycan, Z. ve Kanungo, R. N. (2000). Toplumsal kültürün kurumsal kültür ve insan kaynakları uygulamaları üzerine etkileri. Z. Aycan (Ed), Türkiye'de yönetim, liderlik ve insan kaynakları uygulamaları içinde (ss. 25-47). Ankara: Türk Psikologlar Derneği Yayınları

Aydın, İ. (2017). Paternalist yönetim. A. Kasapoğlu, A. Ç. İlhan ve Z. Güler (Ed), Prof. Dr. Mahmut Tezcan'a armağan içinde (ss. 152-167). Ankara: Ankara Üniversitesi Eğitim Bilimleri Fakültesi Yayınları, No: 224. 
Balcı, A. (2013). Sosyal bilimlerde araştırma: Yöntem teknik ve ilkeler (10. Basım). Ankara: PegemA Yayıncılık.

Beauchamp, T. L., and Childress, J. F. (1994). Principles of biomedical ethics. New York, NY: Oxford UniversityPress.

Beaver, A. R. (1987). Personal autonomy through education (Unpublished doctoral dissertation). Retrieved from http://eprints.nottingham.ac.uk/13356/

Blokland, H. (1997). Freedom and culture in western society. London: Routledge.

Bryman, A. E., and Cramer, D. (2002) Quantitative data analysis with SPSS Release 10 for Windows: A guide for social scientists. East Sussex: Routledge.

Büyüköztürk, Ş. (2010). Sosyal bilimler için veri analizi el kitabı. Ankara: PegemA Yayıncilık.

Canbolat, E. Ö., Beraha, A., Çeliksoy, E. ve Türker, Y. (2010). Türk liderlik profili: Türk siyasi liderleri üzerine niteliksel bir çalışma. Sosyal ve Beşeri Bilimler Dergisi, 2(2), 37-45. https://dergipark.org.tr/en/download/article-file/117240 adresinden edinilmiştir.

Cevizci, A. (2000). Paradigma felsefe sözlüğ̈̈ (4. Basım). İstanbul: Paradigma Yayınlar1.

Chen, H. Y., and Kao, H. S. R. (2009). Chinese paternalistic leadership and nonChinese subordinates' psychological health. The International Journal of Human Resource Management, 20(12), 2533-2546. doi: 10.1080/09585190903363839

Chen, X. P., Eberly, M. B., Chiang, T. J., Farh, J. L., and Cheng, B. S. (2014). Affective trust in Chinese leaders linking paternalistic leadership to employee performance. Journal of Management, 40(3), 796-819. doi: $10.1177 / 0149206311410604$

Cheng, B. S. (1995). Paternalistic authority and leadership: A case study of a Taiwanese CEO. Bulletin of the Institute of Ethnology Academic Sinica, 79(3), 119-173.

Cheng, B. S., and Jen, C. K. (2005). The contingent model of paternalistic leadership: Subordinate dependence and leader competence. Annual Meeting of Academy of Management. $\quad$ Retrieved from http://citeseerx.ist.psu.edu/viewdoc/download?doi=10.1.1.616.3308\&rep=rep1 \&type $=$ pdf

Cheng, B. S., Chou, L. F., and Farh, J. L. (2000). A triad model of paternalistic leadership: The constructs and measurement. Indigenous Psychological Research in Chinese Societies, 14(1), 3-64. 
Cheng, B. S., Chou, L. F., Wu, T. Y., Huang, M. P., and Farh, J. L. (2004). Paternalistic leadership and subordinate responses: Establishing a leadership model in Chinese organizations. Asian Journal of Social Psychology, 7(1), 89117. doi: 10.1111/j.1467-839X.2004.00137.x

Chou, H. J. (2012). Effects of paternalistic leadership on job satisfaction-regulatory focus as the mediator. International Journal of Organizational Innovation (Online), 4(4), 62-85. Retrieved from http://www.ijoionline.org/attachments/article/30/FINAL\%20ISSUE\%20VOL\%204\%20NUM $\% 204 \% 20$ SPRING\%202012.pdf\#page $=62$

Chu, P. C., and Hung, C. C. (2009). The relationship of paternalistic leadership and organizational citizenship behavior: The mediating effect of upward communication. Journal of Human Resource and Adult Learning, 5(2), 66-73. Retrieved from http://www.hraljournal.com/Page/8\%20Chu\%20Paoching.pdf

Cohen, E. S. (1985). Autonomy and paternalism: Two goals in conflict. Law, Medicine and Health Care, 13(4), 145-150. doi: 10.1111/j.1748720X.1985.tb00909.x

Conly, S. (2013). Against autonomy: Justifying coercive paternalism. Cambridge: Cambridge University Press.

Coşkun, V. (2000, 8 Ağustos). Paternalizm ve avrupa. Radikal. http://www.radikal.com.tr/2000/08/10/yorum/pat.shtml adresinden erişilmiştir.

Cserne, P. (2008). Freedom of choice and paternalism in contract law: Prospects and limits of an economic approach (Unpublished doctoral dissertation). Retrieved from https://ediss.sub.uni-hamburg.de/volltexte/2008/3765/pdf/edisscserne.pdf

Dictionary Oxford English. (1971). Oxford [England]: Oxford University Press. Compact edition. Volume I (1971).

Dworkin, G. (1983). Paternalism: Some second thoughts. In R. Sartorius (Ed.), Paternalism. Minneapolis, MN: University of Minnesota Press.

Dworkin, G. (2002). Paternalism. Retrieved from http://plato.stanford.edu/entries/paternalism

Erben, G. S., and Güneşer, A. B. (2008). The relationship between paternalistic leadership and organizational commitment: Investigating the role of climate regarding ethics. Journal of Business Ethics, 82(4), 955-968. doi: $10.1007 / \mathrm{s} 10551-007-9605-\mathrm{z}$

Ersoy, N. C., Born, M. P., Derous, E., and Van Der Molen, H. T. (2012). The effect of cultural orientation and leadership style on self-versus other-oriented organizational citizenship behaviour in Turkey and the Netherlands. Asian Journal of Social Psychology, 15(4), 249-260. doi: 10.1111/j.1467839X.2012.01380.x 
Farh, J. L., and Cheng, B. S. (2000). A cultural analysis of paternalistic leadership in Chinese organizations. In J. T. Li, A. S. Tsui, and E. Weldon (Eds.), Management and organizations in the chinese context (pp. 84-127). London: Palgrave Macmillan.

Farh, J. L., Cheng, B. S., Chou, L. F., and Chu, X. P. (2006). Authority and benevolence: Employees' responses to paternalistic leadership in china. In A. S. Tsui, Y. Bian, and L. Cheng (Eds.), China's domestic private firms: Multidisciplinary perspectives on management and performance (pp. 230-260). New York, NY: Sharpe.

Gray, C. B. (Ed.). (2013). The philosophy of law: An encyclopedia (Vol. 1743). New York, NY: Taylor and Francis.

Hair, J. F., Anderson, R. E., Babin, B. J., and Black, W. C. (1998). Multivariate data analysis: A global perspective (5th ed.). New Jersey, NJ: Prentice Hall Inc.

Harris, J. (1985). The value of life. London: Routledge.

Häyry, H. (1998). Paternalism. In R. F. Chadwick (Ed.), Encyclopedia of applied ethics (Volume 3), (pp. 449-457). New York, NY: Academic Press.

Husak, D. (2010). Paternalism and consent. In F. G. Miller, and A. Wertheimer (Eds.), The ethics of consent: Theory and practice. New York, NY: Oxford University Press.

Kant, I. (1995). Ahlak metafiziğinin temellendirilmesi [Groundwork for the metaphysics of morals]. (İ. Kuçuradi, Çev.). Ankara: Felsefe Kurumu Yayınları (1785)

Kim, U. M. (1994). Significance of paternalism and communalism in the occupational welfare system of Korean firms: A national survey. In U. Kim, H. C. Triandis, C. Kağıtçıbaşı, S. C. Choi and G. Yoon (Eds.), Individualism and collectivism: Theory, method and applications, (pp. 251-266). Thousand Oaks, CA: Sage

Kline, P. (1979). Psychometrics and psychology. London: Academic Press.

Kline, R. B. (2005). Principles and practice of structural equation modeling. NewYork, NY: Guilford Publications.

Köksal, O. (2011). Paternalizm ile algılanan örgütsel adalet arasındaki ilişkinin tespitine yönelik bir araştırma. Cumhuriyet Üniversitesi İktisadi ve İdari Bilimler Fakültesi Dergisi, 12(2), 159-170. https://www.trdizin.gov.tr/publication/paper/detail/TVRNd09UTXdNQT09 adresinden edinilmiştir.

Lau, W. K. E. (2012). A study of effective leadership in the Chinese context. (Unpublished doctoral dissertation). Retrieved from https://digital.library.unt.edu/ark:/67531/metadc149628/m1/1/ 
Martínez, P. G. (2003). Paternalism as a positive form of leader-subordinate exchange: Evidence from Mexico. Management Research: Journal of the Iberoamerican Academy of Management, 1(3), 227-242. doi: $10.1108 / 15365430380000529$

Martinez, P. G. (2005). Paternalism as a positive form of leadership in the Latin American context: Leader benevolence, decision-making control and human resources management practices. In M. Elvira, and A. Davila (Eds.), Managing human resources in Latin America: An agenda for international leaders (pp. 7593). London: Routledge.

Mathur, P., Aycan, Z., and Kanungo, R. N. (1996). Work cultures in Indian organisations: A comparison between public and private sector. Psychology and Developing Societies, 8(2), 199-222. doi: 10.1177/097133369600800202

Mill, J., S., (2009). Hürriyet üstüne [On Libert]. (M. Destel, Çev.). Ankara: Liberte Yayınlar1. (1859).

Miller, R. B. (2003). Children, ethics, and modern medicine. Bloomington: Indiana University Press.

Niu, C. P., Wang, A. C., and Cheng, B. S. (2009). Effectiveness of a moral and benevolent leader: Probing the interactions of the dimensions of paternalistic leadership. Asian Journal of Social Psychology, 12(1), 32-39. doi: 10.1111/j.1467-839X.2008.01267.x

Paulo N. (2015). The bite of rights in paternalism. In Schramme T. (Eds.), New perspectives on paternalism and health care. Library of ethics and applied philosophy (pp. 127-141). Cham: Springer.

Pellegrini, E. K. (2006). A cross-cultural investigation of the relations among organizational justice, paternalism, delegation and leader-member exchange (LMX) relationships (Published doctoral dissertation). Retrieved from Proquest Dissertations and Theses database (UMI No. 3215246). https://search.proquest.com/openview/5c893b573fe882fa2608b4a6d3b3a037/1 ?pq-origsite $=$ gscholar $\& \mathrm{cbl}=18750 \&$ diss $=\mathrm{y}$

Pellegrini, E. K., and Scandura, T. A. (2006). Leader-member exchange (LMX), paternalism, and delegation in the Turkish business culture: An empirical investigation. Journal of International Business Studies, 37(2), 264-279. doi: 10.1057/palgrave.jibs.8400185

Pellegrini, E. K., and Scandura, T. A. (2008). Paternalistic leadership: A review and agenda for future research. Journal of Management, 34(3), 566-593. doi: $10.1177 / 0149206308316063$

Pellegrini, E. K., Scandura, T. A., and Jayaraman, V. (2010). Cross-cultural generalizability of paternalistic leadership: An expansion of leader-member 
exchange theory. Group and Organization Management, 35(4), 391-420. doi: $10.1177 / 1059601110378456$

Redding, S. G. (1990). The spirit of Chinese capitalism. Berlin: Walter de Gruyter.

Saher, N., Naz, S., Tasleem, I., Naz, R., and Kausar, S. (2013). Does paternalistic leadership lead to commitment? Trust in leader as moderator in Pakistani context. Interdisciplinary Journal of Contemporary Research in Business, 5(1), 443-455. Retrieved from https://pdfs.semanticscholar.org/6088/64a90319a05722be4db4e9a5d30a1caf9b e1.pdf

Saylık, A. (2017). Okul müdürlerinin paternalist liderlik davranışları ile Hofstede’nin kültür boyutları arasındaki ilişki (Yayımlanmamış doktora tezi). Ankara Üniversitesi Eğitim Bilimleri Enstitüsü, Ankara.

Sennett, R. (2005). Otorite [Authority]. (K. Durand, Çev.). İstanbul: Ayrıntı Yayınları.

Shinebourne, E. A., and Bush, A. (1994). For paternalism in the doctor-patient relationship. In R. Gillon (Ed.), Principles of health care ethics (pp. 399-408). New York, NY: Wiley.

Silin, R. H. (1976). Leadership and values: The organization of large-scale Taiwanese enterprises. Cambridge: Harvard UniversityPress.

Suber, P. (1999). Paternalism. In C. B. Gray (Ed.), Philosophy of law: An encyclopedia (pp. 632-635). New York, NY: Garland Publication.

Sun, J. M., and Wang, B. (2009). Servant leadership in China: Conceptualization and measurement. In W. H. Mobley, and Y. W. Ming Li (Eds.), Advances in global leadership (pp. 321-344). Bingley: Emerald Group Publishing Limited.

Sümer, N. (2000). Yapisal eşitlik modelleri: Temel kavramlar ve örnek uygulamalar. $\begin{array}{llll}\text { Türk Psikoloji } & \text { Yazilari, } & \text { 3(6), }\end{array}$ https://www.researchgate.net/publication/281981476_Yapidotlesssal_esitlik_m odelleri_Temel_kavramlar_ve_ornek_uygulamalar adresinden edinilmiştir.

Uhl-Bien, M., and Maslyn, M. (2005, August). Paternalism as a form of leadership: Differentiating paternalism from leader-member exchange. Paper presented an oral or poster presentation at the Meeting of the Academy of Management, Honolulu, Hawaii.

Uhl-Bien, M., Tierney, P., Graen, G., and Wakabayashi, M. (1990). Company paternalism and the hidden investment process: Identification of the "right type" for line managers in leading Japanese organizations. Group and Organization Studies, 15(4), 414-430. doi: 10.1177/105960119001500406

Van De Veer, D. (2014). Paternalistic intervention: The moral bounds on benevolence. New Jersey, NJ: Princeton University Press. 
Veatch, R. M., and Spicer, C. M. (1994). Against paternalism in the patient-physician relationship. In R. Gillon (Ed.), Principles of health care ethics (pp. 409-419). New York, NY: Wiley.

Weber, M. (1968). The types of legitimate domination, In G. Roth and C. Wittich (Eds.), Economy and society (pp. 212-216). New York, NY: Bedminster.

Westwood, R. I. (1997). Harmony and patriarchy: The cultural basis for paternalistic headship among the overseas Chinese. Organization Studies,18(3), 445-480. doi: $10.1177 / 017084069701800305$

Westwood, R., and Chan, A. (1992) Headship and leadership. In R. Westwood (Ed.), Organizational behaviour: Southeast asian perspectives. Hong Kong: Longman.

Yardımcı, C. (2010). Paternalistik liderlik davranışlarının iş tatmini üzerindeki etkisi: Bankacılık sektörü üzerinde bir uygulama (Yayımlanmamış yüksek lisans tezi). Hacettepe Üniversitesi Sosyal Bilimler Enstitüsü, Ankara.

Yeh, H. R., Chi, H. K., and Chiou, C. Y. (2008). The influences of paternalistic leadership, job stress, and organizational commitment on organizational performance: An empirical study of policemen in Taiwan. The Journal of International Management Studies, 3(2), 85-91. Retrievd from http://203.72.2.146/bitstream/987654321/27172/1/The\%20Influences\%20of\%2 OPaternalistic.pdf

Yetim, N., and Yetim, Ü. (2006). The cultural orientations of entrepreneurs and employees' job satisfaction: The Turkish small and medium sized enterprises (SMEs) case. Social Indicators Research, 77(2), 257-286. doi: 10.1007/s11205005-4851-x 


\title{
Development of The Paternalist Leadership Behavior Scale of School Principals: Validity and Reliability Study ${ }^{1}$
}

\begin{tabular}{lccc}
\hline ARTICLE TYPE & Received Date & Accepted Date & Published Date \\
Research Article & 04.19 .2019 & 03.20 .2020 & 04.01 .2020 \\
\hline
\end{tabular}

\author{
Ahmet Saylık \\ Siirt University \\ Inayet Aydın \\ Ankara University
}

\begin{abstract}
As an organizational and managerial approach, paternalist leadership is generally considered as a positive value and a functional approach by relying on a deep cultural heritage in Asian societies. Although the concept of studies aimed at determining the dimensions of paternalist leadership has generally limited to benevolent, morality and authoritarianism, it is stated that paternal approaches are essentially exploitative, have some limitations on autonomy, contain some kind of interventionism, find the beneficiary insufficient, and mask the authoritarianism with the compassion and love of the father. The aim of this study is to develop a reliable and valid measurement tool to measure the paternalist behavior of school principals. For this purpose, 245 teachers working in primary schools in Ankara, Mamak, Gölbaşı and Çankaya district centers were applied. Expert opinions were used for the scope validity of the study. As a result of the Exploratory Factor Analysis (EFA) applied for the construct validity of the study, the variance explained by the scale was determined as $67.16 \%$ and a structure consisting of 5 factors was obtained. According to the results of Confirmatory Factor Analysis (CFA) conducted to confirm the AFA results, the fit index of the 5-factor structure was found to be at a good level. On the other hand, Cronbach's Alpha coefficient was used for the reliability analysis of the paternalist leadership scale, and the corrected item total correlations for the distinguishing characteristics of the scale items were examined and it was found that the scale was a reliable measurement tool.
\end{abstract}

Keywords: Paternalist leadership, leadership behaviors of school principals, scale development, validity, reliability.

${ }^{1}$ This study was expanded by adding new dimensions into the scope of the PhD thesis titled The Relationship between Paternalistic Behaviours of School Principals and Hofstede's Cultural Dimensions", which took the Paternalistic (Fatherly) Leadership Behaviours of Administrators Scale developed by Prof Dr. İnayet Aydın and then was prepared by Ahmet Saylık under the supervision of Prof. Dr. İnayet Aydın. The study was presented as an oral presentation in "EYFOR-8 International Education Management Forum" held in Ankara between October 19 and 21, 2017.

${ }^{2}$ Corresponding Author: Assist. Prof. Dr., Faculty of Education, E-mail: ahmetsaylik@gmail.com, https://orcid.org/0000-0001-7754-2199

${ }^{3}$ Prof. Dr., Faculty of Educational Sciences, Email: iaydin@ankara.edu.tr, https://orcid.org/0000-0002$7522-8961$ 


\section{Purpose and Significance}

Paternalism comes from the Latin pater meaning to act like a father, or to treat another person like a child (Suber, 1999). In other words, paternalism means to treat a person as the father treats his children (Aycan, 2006). It is the essence of paternalism that a father makes decisions for his children rather than letting them make their own decisions, on the grounds that "father knows the best" (Andre and Velasquez,1991). Therefore, paternalism can be defined as making decisions on behalf of people (Shinebourne and Bush, 1994). According to Aydin (2017), paternalism involves a conflict of two important values: 1) the value we place on the freedom of persons to make their own choices about how they will lead their lives, and 2) the value we place on promoting and protecting the well-being of others. Therefore, paternalism involves two parties, one of which is stronger (individual-individual, state-state) and is the direct interference of the stronger with the right to choose and freedom of the weaker with the false promise of protection and well-being.

The superior and subordinate relationship in paternalism, also known as fatherliness or patriarchy, resembles the parent-child relationship. In this approach, while the superior protects and guides the subordinate and makes decisions on behalf of the subordinate for his/her well-being, the subordinate devotedly follows the superior in return. Paternalism is rooted in the traditional patriarchal structure in the family and state. The structure involved in these two fundamental bodies has been transferred into workplaces and organizations over time (Aycan and Kanungo, 2000). From this point of view, it can be stated that individuals transfer the informal structure values that reflect the social culture to the organizations that they belong to.

Paternalistic leadership is a leadership style that combines open and strong authority with interest, courtesy and moral values (Silin, 1976). In this respect, paternalistic leadership is thought to be an effective leadership style in organizations in Turkey. However, schools have more specific structures compared to other organizations.

Paternalistic leadership dimensions. Analyses related to paternalism raise some controversial issues. The assumption that the paternalistic leadership has an organic relationship with cultural ties has led the context to be addressed in different ways in the Eastern and Western literature. In fact, especially English-speaking cultures, mainly in North America and Europe, have harshly criticized the fact that Eastern cultural clusters consider the paternalistic leadership as a desirable and functional approach. This study aimed at putting forward the dimensions of the paternalistic leadership without shifting to an emic-ethical ground. While doing so, utmost attention was paid to avoiding a parochial Eurocentric perspective. The fact that the paternalistic leadership has historical ties with Eastern culture and with the Confucian tradition in particular, seems to have overshadowed the objective discussion of this phenomenon and concept. Studies conducted to determine the paternalistic leadership dimensions (Cheng, Chou, Wu, Huang and Farh, 2004; Farh and Cheng, 2000; Farh, Cheng, Chou and Chu, 2006; Pellegrini and Scandura, 2006) 
have limited the concept to the dimensions of benevolence, morality, and authoritarianism. Though some there are some studies that differentiate from this approach (Aycan, 2006), there is almost no study which demonstrates the facts that paternalism has limitations on freedom and autonomy, the paternal actions involve some kind of interventionism, the paternalist finds the beneficiary inadequate, and all these approaches mentioned are nurtured-maintained by authoritarianism. The paternalistic leadership has ignored the features mentioned above because of its compatibility with Eastern culture.

Paternalism and freedom-autonomy. Autonomy is the concept that consists of the combination of autos meaning self, and of nomos meaning law (Cevizci, 2000). There is a deep contrast between the two concepts considering that autonomy means to act independently and paternalism means forcing for something.

The ethical problem related to paternalism has been how a person sees the right to behave individuals under his/her auspices in a paternalistic manner, regardless of the situation. Therefore, paternalism is seen as a violation of individual rights such as autonomy and the right to choose (Blokland, 1997). According to Gray (2013), paternalism states that people are trying to protect themselves from themselves as if they are more important than their freedom. Yet, Mill (2009) points out that it is not acceptable to abandon autonomy for the sake of the principle of utility and thus paternalism must be strictly avoided.

Paternalism and interventionism. Paternalism is considered as a kind of intervention approach with the life of the other (Agich, 2003; Aycan, 2006; Conly, 2013; Dworkin, 2002; Harris, 1985; Husak, 2010; Mill, 2009; Miller, 2003; Paulo, 2015; Shinebourne and Bush, 1994; Van De Veer, 2014; Veatch and Spicer, 1994). This intervention often occurs without respect for the wishes and decisions of the other (Harris, 1985) and with an undesirable behavioural manner towards the other (Dworkin, 1983).

Another controversial issue is whether the underlying motive of the intervention occurring in the paternal approach is indeed for the benefit of the beneficiary or for the implicit and immoral interests of the paternalist. Kim (1994) argues that the issue of intention determines whether paternalism is benevolent or exploitative. It is suggested that paternalism has an exploitative side (Aycan, 2006; Uhl-Bien and Maslyn, 2005) and thus may not be as philanthropic as it essentially promises (Pellegrini and Scandura, 2008).

Paternalism and finding inadequacy. It can be suggested that one of the most fundamental features of paternalism is that the paternalist finds the person under care inadequate in terms of cognitive functions such as rational thinking and decision making, using and analysing information and making inferences. The individual who behaves paternally is in the opinion of I know what is best for you and somehow makes his/her circle feel this as a part and by force of this role. According to Aycan (2006), the paternalistic leader's status is ascribed by the virtue of his position, age, 
and experience, and therefore his power and authority is legitimated. Studies (Silin, 1976; Westwood, 1997; Westwood ve Chan, 1992) show that the paternalist has a didactic role on the subordinates, especially in the management field. Accordingly, it is nurtured on the assumption that there is an unequal accumulation of knowledge between the superiors and the subordinates and that the subordinates are each a student who is in need of training. According to the assumption, the paternalist is an authority who knows what is best for the subordinates.

Family atmosphere. When production-oriented, scientific and close-supervised formal approaches in organization and management science failed to satisfy, the efficiency was increased by creating a family atmosphere in the organization (Sennett, 2005). Aycan (2006) states that the paternalistic leader has some approaches including creating a family atmosphere in the workplace by behaving like a father to subordinates, giving fatherly advice to subordinates in their professional as well as personal lives, establishing close and individualized relationships with subordinates knowing every subordinate in person and being concerned with their welfare, getting involved in the non-work domain by attending important events such as wedding, funeral ceremonies and graduations and providing help and assistance.

Authoritarianism. What is implied from the authoritarian leadership is the tendency or behaviour of employers to provide absolute authority and control over the employees and to expect unquestioned obedience from them (Farh and Cheng, 2000; Cheng et al., 2004; Farh et al., 2006).

It is stated that in Turkey paternalistic values are significantly crucial in social culture (Aycan et. al., 2000). The identity of the organization manager has been shaped after the relationship style emerging with the merger of affection and power distance between the father and son in the family structure with the collectivist and hierarchical culture structure has had reflection on the work life over time (Canbolat, Beraha, Çeliksoy and Türker, 2010). The Paternalistic Manager Behaviours Scale, developed to determine the paternalistic leadership behaviours of individuals who manage education institutions, which are among the crucial institutions whose input and output are composed of human, is expected to contribute to the field of education management.

\section{Method}

In this part, which is given with the title of process steps in a gradual stage of scale development; Findings related to the creation of item pool and pre-application of the scale, pre-application, item-total correlation, exploratory and confirmatory factor analyzes.

\section{Results}

Exploratory Factor Analysis (EFA) and Confirmatory Factor Analysis (CFA) were used to determine the validity and reliability of the paternalistic leadership scale in schools. It was found that the data set whose KMO value was .93 and Barlett test 
was found significant $\left(\chi^{2}=5,519.54, \mathrm{df}=496, p<.01\right)$ was suitable for factor analysis. Factor load values of the items ranged from .49 to .84 . The total correlations of the items were .49 to .73 and Cronbach's Alpha reliability coefficient was $\alpha=.82$ in the first factor; .61 and .52 and $\alpha=.90$ in the second factor; .62 and .7 and $\alpha=.85$ in the third factor; .60 and .82 and $\alpha=.89$ in the fourth factor; .59 and .79 , and $\alpha=.92$ in the fifth factor. Moreover, the correlation of the 30 items in the scale with each other was found to be quite high. According to the obtained values, the items in the scale were found to have good discriminative characteristics. The analyzes revealed that the variance rate explained by each factor was $9.1 \%$ in the first factor; $17.17 \%$ in the second factor; $10.32 \%$ in the third factor; $12.01 \%$ in the fourth factor and $18.56 \%$ in the fifth factor. The total variance explained by all five factors was $67.16 \%$. The model obtained from EFA was tested with CFA. The fit of the model was assessed with RMSEA, CFI, GFI, AGFI, NFI and RMR compliance criteria. As a result of the analyses conducted, compliance values were calculated as .041 for RMSEA, .969 for CFI, .880 for GFI, .902 for NFI and .848 for AGFI.

\section{Discussion and Conclusions}

The Paternalistic LeadershipBehaviours Scale is a measurement tool consisting of 30 items and 5 sub-dimensions developed to measure the paternalistic behaviours of school principals. The dimension of family atmosphere measures the level of creating a family atmosphere among employees in and out of school. There are four items in this sub-dimension. Some of these items are as "S/he sees her/himself as the family elder in school" and "S/he values creating a family atmosphere in school". The highest score that can be obtained from this sub-dimension is 20 while the lowest score is 4 . High scores indicate that school principals have a high level of behaviour towards creating a family atmosphere among employees in and out of school. The dimension of benevolence measures the level of goodwill of principals in school in their managerial attitudes and behaviours. This sub-dimension includes 9 items, some of which are as "S/he gives advices to teachers related to their personal lives", "S/he attends important events (e.g. wedding, funeral ceremonies, graduations, etc.)" and "S/he treats teachers in good faith". The highest score than can be obtained from this sub-dimension is 45 and the lowest score is 9. High scores indicate that school principals exhibit a high level of behaviour related to benevolence. The dimension of authoritarianism measures the level of authoritarian behaviour of school principals containing 4 items some of which are as "Teachers are uncomfortable about making decisions on their own" and "Principals expect the tasks to be done without criticism". The highest score to obtain from this sub-dimension is 20 while the lowest score is 4 . High scores indicate that school principals exhibit a high level of authoritarian behaviour. The dimension of interventionism measures the level of intervening of school principals containing 5 items some of which are as " $\mathrm{S} /$ he intervenes with the appearance of teachers (e.g. hair, clothes, etc.)" and "S/he ignores requests of teachers in managerial decisions and practices (e.g. assignments, shift, course hours, class distributions, equipment distributions, etc.)." The highest score to obtain from this sub-dimension is 25 while the lowest score is 5 . High scores indicate that school 
principals show a high level of interventionist behaviors. The dimension of finding inadequate measures the level of finding teachers inadequate including 8 items, some of which are as "S/he does not take into account the decisions of teachers even if teachers are asked about their opinions on a specific task", "S/he thinks that teachers are unable to solve problems to occur when $\mathrm{s} /$ he is out of school" and "S/he makes teachers feel that $\mathrm{s} / \mathrm{he}$ is a huge grace due to her/his position". The highest score to obtain from this sub-dimension is 40 while the lowest score is 8 . High scores indicate that school principals show a high level of finding employees inadequate.

The scale produces total scores. The lowest score to obtain from the scale is 30 while the highest is 150 . High scores show that school principals exhibit high level of paternalistic behaviours. There are no negative statements and thus, there is no reverse scoring in the scale. High Alpha coefficients related to the sub-dimensions of the scale (Family Atmosphere $=.82$, Benevolence $=.90$, Authoritarianism $=.85$, Interventionism $=.89$ and Finding Inadequate $=.92$ ) indicate that items included in the sub-dimensions are consistent with each other. EFA and CFA results confirmed the validity of the scale.

As a result of the findings obtained from exploratory and confirmatory factor analyses, the Paternalistic Leadership Scale is a measurement tool with sufficient psychometric properties to measure the paternalistic (fatherly) behaviours of school principals in their managerial decisions and practices in their relations with teachers. 